Thorax (1969), 24, 603.

\title{
Dysphagia megalatriensis
}

\author{
B. T. LE ROUX AND M.A. W ILLIA M S \\ From the Thoracic Unit, University of Natal, Durban, Natal, South Africa
}

Death from haematemesis is recorded in a patient with a giant left atrium which had cause dysphagia of such severity that a plastic naso-gastric faeding tube had been introduced and retained for some days. Vascular causes of dysphagia are briefly reviewed. It is thought that the rarity of dysphagia with left atrial enlargement justifies its recognition by a new term.

An enlarged left atrium commonly displaces the oesophagus and, in patients with mitral valve disease, it is common practice to record and relate the extent of left atrial enlargement radiographically with the oesophageal lumen opacified with barium. In these circumstances even when oesophageal displacement is considerable dysphagia is unusual. It is the purpose of this paper to record an example not only of dysphagia consequent upon left atrial enlargement but of ossophageal and systemic arterial erosion from the same cause and as a mode of death. Since dysphagia is further qualified in other circumstances-as dysphagia nervosa or dysphagia lusoria-it is suggested that, when left atrial enlargement is of such proportion that dysphagia results, this circumstance be called dysphagia megalatriensis. Other vascular causes of dysphagia are briefly reviewed.

\section{CASE REPORT}

A woman of 26 years, in whom rheumatic mitral valve disease had first been recognized at the age of 20 , sought further advice because of a recent deterioration in effort tolerance, and was admitted to hospital. The clinical findings were those of predominant mitral regurgitation with cardiac failure. Radiographically, the left atrium was of proportions which prompted the descriptive term 'giant', and there were Kerley 'B' lines. Electrocardiographically the rhythm was that of atrial fibrillation and there was evidence of biventricular enlargement. At catheterization the mean pulmonary arterial pressure was shown to be $42 \mathrm{~mm}$. $\mathrm{Hg}$ and the mean wedge pressure $30 \mathrm{~mm}$. $\mathrm{Hg}$. After a period of bed rest and management with digitalis and a diuretic, mitral valve repair was undertaken through a left lateral thoracotomy and with cardiopulmonary bypass. The left atrium was greatly enlarged; the aortic cusp of the mitral valve was voluminous and over-rode a furled, shrunken mural cusp. Two anteriorly and two posteriorly placed plicating sutures corrected incompetence, with a resultant mitral orifice which easily accepted two fingers. Recovery was uneventful, and a month after operation the patient was discharged well. Six months later she was again unwell with symptoms suggestive of acute rheumatic fever, and during this illness the clinical features of mitral incompetence recurred and were ingravescent. Radiographically the left atrium became even larger (Fig. 1a, b) and she developed dysphagia, the radiographic concomitant of which was compression of the remarkably displaced, barium-filled oesophagus (Fig. 2). Dysphagia progressed, and to facilitate hydration, which had become a problem, a nasogastric tube was passed and retained for several days. Mitral valve replacement was planned. The patient died abruptly from exsanguinating haematemesis while awaiting surgical management.

At necropsy a giant left atrium was seen to compress the oesophagus; there was circumferential erosion of the oesophageal mucosa over an area $4 \mathrm{~cm}$. in length, within the limits of which there was a perforation through the oesophageal wall which in turn communicated with a lateral defect in an intercostal artery which crossed to the right behind the oesophagus. The plicating sutures were easily recognized - they constituted part of a bridge across each commissure and did nothing to diminish incompetence. which was gross. It is assumed that dysphagia was from oesophageal compression from enlargement of the left atrium and that oesophageal and systemic arterial erosions were related to the presence over some days of the plastic feeding tube within the oesophageal lumen. The eroded oesophageal lumen, with clot at the site of the oesophago-arterial communication, is shown in Figure 3. 
(a)

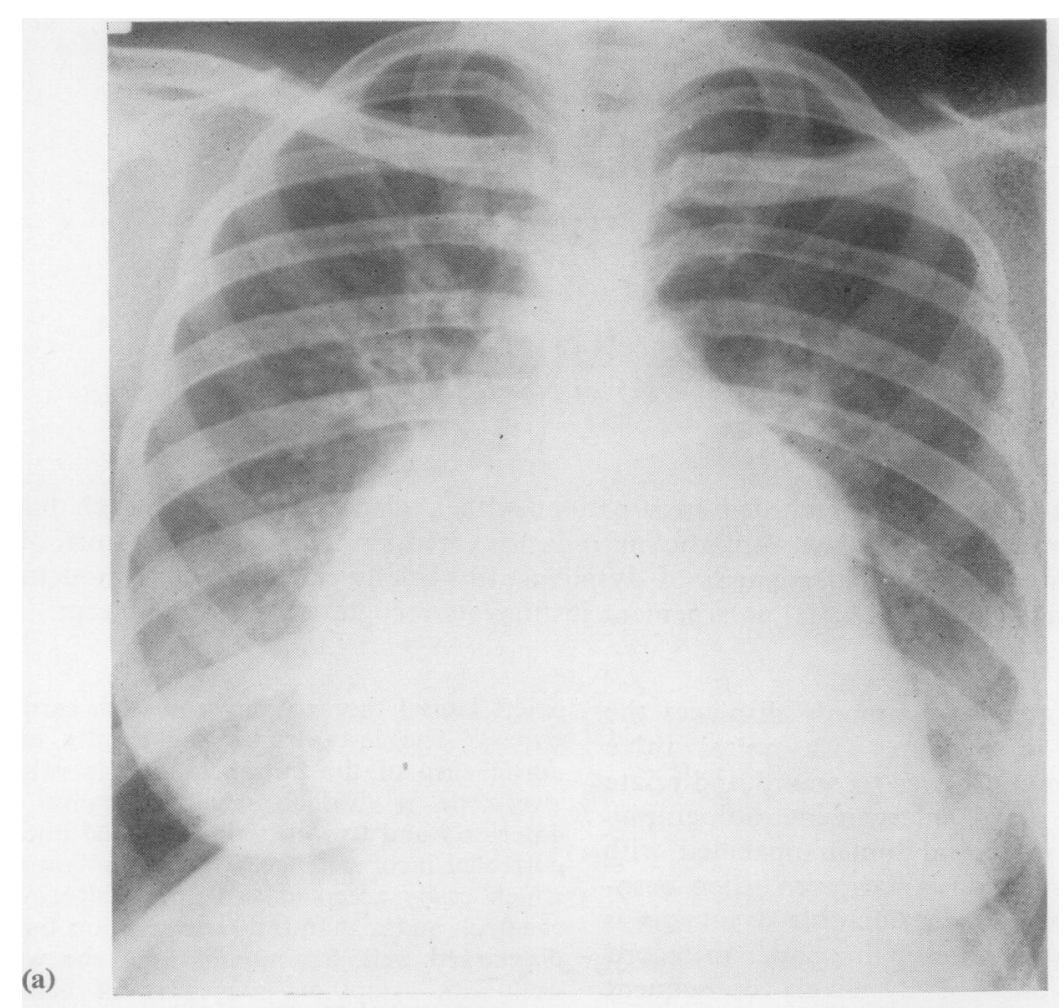

FIG. 1. Postero-anterior chest radiographs made (a) before plication of the mitral annulus and $(b)$ seven months later, when dysphagia was severe. 


\section{DISCUSSION}

Vascular causes of dysphagia are not common. Dysphagia lusoria is that which is consequent upon retro-oesophageal extension from left to right of an anomalously arising right subclavian artery. Bayford (1789) recorded the post-mortem findings in a woman who died from starvation after a life-time of dysphagia, and in whom swallowing had frequently been accompanied by a sense of suffocation and impending death. The anatomical anomaly was considered a lusus naturae and is now classified with the other varieties of vascular ring about the trachea and oesophagus-double aortic arch, right aortic arch with a left ligamentum arteriosum or persistent ductus, and anomalous innominate and left common carotid arteries (Gross, 1955). An anomalously arising left pulmonary artery (Dumler, 1966), an anomalous branch of a left bronchial artery (McCorkle, 1950), and an abberant intercostal (Warden, 1961) which passed anterior to the oesophagus, have been recorded as causes of dysphagia. Dysphagia may be caused by aortic aneurysm, by 'unfolding' of the aorta, and its great branches, and has been recorded from compression of the oesophagus between a failing left ventricle and a tortuous, sclerotic aorta (Keates and Magidson, 1955). To this list of vascular

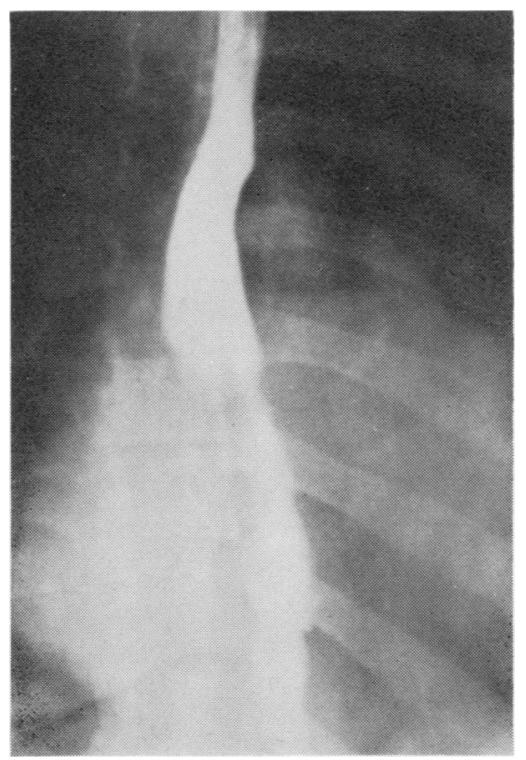

FIG. 2. Obstruction to the passage of barium in the oesophagus is shown.

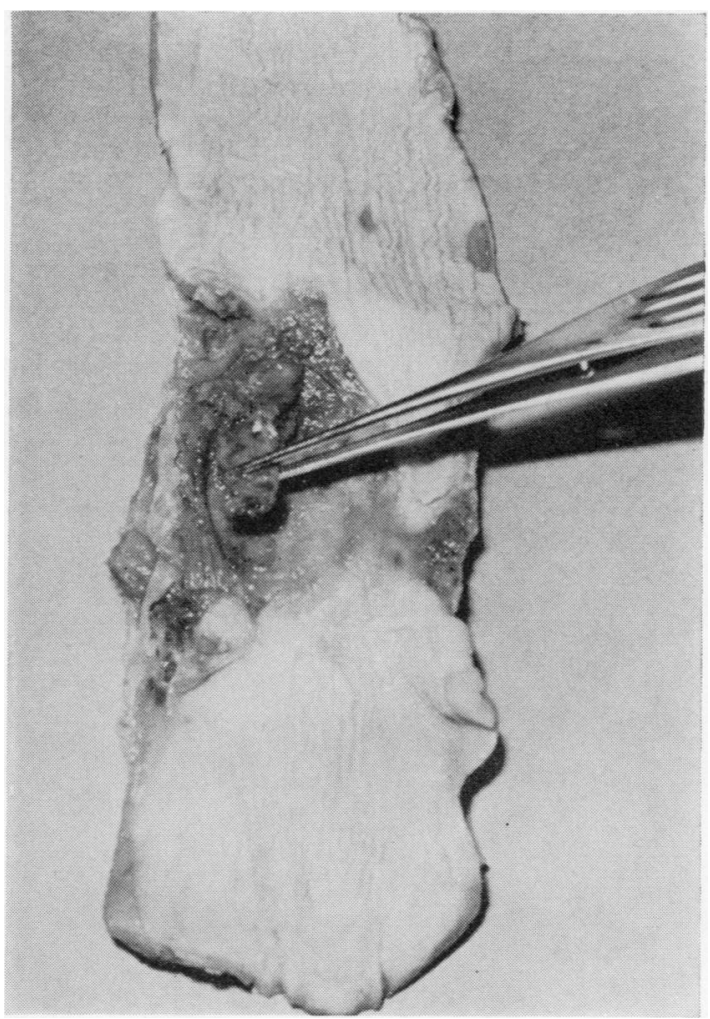

FIG. 3. Post-mortem specimen in which is shown oesophageal erosion and clot which obstructs the site of oesophageal perforation into an intercostal artery.

causes of dysphagia may be added that from left atrial enlargement. Few examples have been recorded-in the light of the frequency of mitral valve disease, surprisingly few (Nichols and Ostrum, 1932; Bloomfield, 1940; Newton and Levine, 1942 ; Tinney, Schmidt, and Smith, 1943 ; Parsonnet, Bernstein, and Martland, 1946 ; Dines and Anderson, 1966). A close anatomical relationship between the oesophagus and the left atrium make it inevitable that the oesophagus is displaced when the left atrium enlarges. Compression of the oesophagus is probably rare because the oesophagus tends to 'slip' to one or other side of the vertebral bodies-more commonly to the right, perhaps because concomitant right ventricular enlargement is associated with rotation of the heart from right to left, anteriorly, so that the left atrium is carried to the right.

A report of oesophageal erosion with giant left atrium has not been found. The retained polythene feeding tube probably contributed-the 
posterior oesophageal wall and the intercostal vessel were compressed between two unyielding structures, the vertebrae and the plastic tube, by the giant left atrium. Retention of a foreign body in the oesophagus is well recorded as a cause of a fatal haematemesis (le Roux, 1964; Sloop and Thompson, 1967).

\section{REFERENCES}

Bayford, D. (1789). An account of a singular case of obstructed deglutition. Mem. med. Soc. London, $2,271$.

Bloomfield, A. L. (1940). Dysphagia with disorders of the heart and great vessels. Amer. J. med. Sci., 200, 289.

Dines, D. E., and Anderson, M. W. (1966). Giant left atrium as a cause of dysphagia. Ann. intern. Med., 65, 758.

Dumler. M. P. (1966). A rare cause of dysphagia; anomalous left pulmonary artery. J. Amer. med. Ass., 197, 513.
Gross, R. E. (1955). Arterial malformations which cause compressiof of the trachea or esophagus. Circulation, 11, 124.

Keates, P. G., and Magidson, O. (1955). Dysphagia associated wit sclerosis of the aorta. Brit. J. Radiol., $28,184$.

le Roux, B. T. (1964). Intrathoracic foreign bodies. Thorax, 19, 203 McCorkle, R. G. (1950). Esophageal obstruction caused by vascula ڤ్లి anomaly; a case report. Dis. Chest, 36, 332.

Newton, F. C., and Levine, S. A. (1942). Decompression of the ches $\overrightarrow{0}$ for dysphagia due to marked cardiac enlargement. J. thorac: Surg., 12, 151 .

Nichols, C. F., and Ostrum, H. W. (1932). Unusual dilatation of the्w left auricle. Amer. Heart J., 8, 205.

Parsonnet, A. E., Bernstein, A., and Martland, H. S. (1946). Massive left auricle with special reference to its etiology and mechanism $\times$ Ibid., 31, 438.

Sloop, R. D., and Thompson, J. C. (1967). Aorto-esophageal fistula report of a case and review of literature. Gastroenterology, 53 , 768.

Tinney, W. S., Schmidt, H. W., and Smith, H. L. (1943). Dysphagia the result of pressure from a dilated left auricle. Proc. Mayo Clin., 18, 476.

Warden, H. D. (1961). Esophageal obstruction due to aberrant intercostal artery; report of a case. Arch. Surg., 83, 745. 